\title{
Preoperative factors affecting visual outcome after unilateral cataract extraction in pediatric age group
}

Shaimaa H. Moustafa ${ }^{a}$, Ghada I. Gawdat ${ }^{\mathrm{b}}$, Mahmoud A. Kamal $^{\mathrm{a}}$, Sherin H. Sadek ${ }^{\mathrm{a}}$

aDepartment of O pthalmology,

Fayoum U niverity, Fayoum

${ }^{\text {b}}$ Department of O phthalmology

Cairo University, Cairo

Correspondence to Sherin $\mathrm{H}$. Sadek, MD, FRCS, 2/7 Zahraa El Maadi, 4th Floor,

Dep. 45, Cairo 11435, Egypt.

Tel: +20 1006232012 .

e-mails:

sh.sadek@gmail.com; shs00@fayoum.edu.eg

Received: May 2019

Revised: Novemer 2019

Accepted: 2019

The Egyptian Journal of Cataract and Refractive Surgery 2019

\begin{abstract}
Purpose
The aim was to analyze preoperative factors that result in a poor postoperative (PO) visual outcome in cases with unilateral cataract, mainly the relationship between preoperative interocular axial length difference (IALD) and PO visual acuity.

Materials and methods

A retrospective chart review of 200 pediatric patients with unilateral congenital cataracts was carried out from 2011 to 2015. A total of 30 participants who had cataract extraction with primary intraocular lens implantation were included, with the performed surgical procedure at an age between 10 months and 11 years older at the time of surgery. Statistical analysis was done.

Results

A total of 30 participants were included in this study who fulfilled all the inclusion criteria and provided complete responses. Mean IALD was $1.37 \mathrm{~mm}$. The mean IALD was $0.26 \mathrm{~mm}$ solely in patients with good visual outcome, whereas children who had a fair and poor outcome, the mean IALD was 1.87 and $2.24 \mathrm{~mm}$, respectively $(P=0.008)$. All the patients who had good visual outcome were compliant with amblyopia therapy, whereas $60 \%$ of patients with the fair visual outcome and $28.50 \%$ of those with poor visual outcome solely were compliant with amblyopia therapy $(P=0.001)$. Mean age at the time of surgery was 39.40 months. Eleven patients had good vision, and $91.9 \%$ of them were younger than 2 years old at the time of surgery $(P=0.001)$.

Conclusion

The smaller the preoperative IALD, the younger the surgical age, the earlier the surgical intervention, and the higher the compliance with amblyopia therapy, the higher is the PO visual acuity in a child with unilateral cataract.
\end{abstract}

Keywords:

cataract, pediatric, unilateral, visual outcome

\section{Introduction}

Refractive error reduction throughout eye growth is known as 'emmetropization.' This process depends principally on effective visual stimulation and visual environment ${ }^{[1]}$, with any disruption consistently ends up in axial myopia development known as formdeprivation myopia ${ }^{[2]}$. The visual outcomes in pediatric cataract improved with screening programs, early cataract detection, early surgical intervention, and innovations in surgical technique together with primary intraocular implantation ${ }^{[3-5]}$. However, determining the prognosis of an individual remains difficult ${ }^{[6]}$. Understanding the factors affecting this prognosis is the concern of recent research studies. Investigators have found that factors affecting the postoperative (PO) visual acuity are the age at the time of surgery, laterality of cataract, and amblyopia therapy compliance ${ }^{[7-9]}$.

Interocular axial length difference (IALD) is of particular interest in a pediatric cohort because
$48 \%$ of pediatric patients with cataracts have an IALD of greater than or equal to $0.5 \mathrm{~mm}$, which is not common in the general adult population ${ }^{[6]}$. The larger absolute IALD could also be a predictor of poor visual outcome ${ }^{[10]}$. The Infant Aphakia Treatment Study Group concluded that there is no definite optical treatment for aphakic infants. The investigators counseled contact lens use for aphakia correction in an infant operated younger than 7 months of age unless its handling and cost are unaffordable for the parents ${ }^{[11]}$. The aim of our study was to assess factors affecting visual outcome in a unilateral pediatric cataract, principally the IALD.

This is an open access journal, and articles are distributed under the terms of the Creative Commons Attribution-NonCommercial-ShareAlike 4.0 License, which allows others to remix, tweak, and build upon the work non-commercially, as long as appropriate credit is given and the new creations are licensed under the identical terms. 


\section{Materials and methods}

The operative sheets of 200 patients with pediatric cataract were collected within the period from 2011 to 2015. Retrospective nonrandomized clinical study of patients who met the inclusion criteria was conducted after approval from our Institutional Ethical Committee. An exploration of the information and medical records of patients who underwent unilateral cataract extraction surgery with primary IOL placement was done.

Eyes were included if they had unilateral cataract surgery with primary IOL implantation at the age between 7 months and 18 years.

Eyes were excluded in cases of complicated cataract, cases developing PO complications as secondary glaucoma, or had signs of retinal or uveal involvement, which might affect the PO visual outcome.

Data collected, as shown in Table 1, included demographic data (sex and date of birth) and clinical information consisting of age at the time of surgery, preoperative axial length of the affected eye and therefore the fellow eye (measurements were repeated until three measurements showed consistent, sharp retinal echo spikes; these three measurements were averaged to yield final axial length) ${ }^{[1]}$, and baseline vision. Baseline visual acuity was assessed in step with the age by the forced choice preferential looking grating (age 7 months -1 year), Cardiff cards (1-2 years old), 3 months logMAR uncrowded Kay pictures (18 months-3 years) or crowded Kay pictures (3-4 years), and crowded Snellen's chart in verbal children over 3-4 years old. Additionally, the visual acuity was divided into three

Table 1 Clinical data of patients

\begin{tabular}{lc}
\hline Characteristics & $N(\%)$ \\
\hline Age at surgery (months) & $10-132$ \\
Mean & 39.40 \\
Preoperative strabismus & \\
$\quad$ No & $12(40.0)$ \\
Yes & $18(60.0)$ \\
Cataract morphology & \\
Lamellar & $8(26.7)$ \\
Nuclear & $9(30.0)$ \\
Posterior & $4(13.3)$ \\
Total & $9(30.0)$ \\
IALD & \\
Minimum & $-2.00 \mathrm{~mm}$ \\
Maximum & $5.50 \mathrm{~mm}$ \\
Mean & $2.32 \mathrm{Mm}$ \\
\hline
\end{tabular}

IALD, interocular axial length difference. categories: good (fixated and followed; central, steady, and maintained or questionably maintained, or Snellen equivalent of 6/12 or better), fair (fixated and followed with strong contralateral preference, or Snellen equivalent higher than $6 / 36$ but worse than 6/12), and poor (poor fixation, restricted following; not central, not steady, not maintained; or $6 / 36$ or worse) ${ }^{[12-14]}$.

Moreover, preoperative strabismus assessed by the prism bar or separate prism sets in step with child cooperation, the morphology of the cataract detected by the portable or table-mounted slit lamp, PO visual acuity (first day, 2 weeks, 1 month, third month, sixth months PO), and the compliance with amblyopia therapy before age 4 years (as a measure of the patient's effort and consistency in patching; half waking hours; and glasses use after cataract surgery) were enclosed.

The patching compliance assessment relied on parental reporting through questions that were asked at every follow-up visit. It had been evaluated retrospectively and therefore the patching compliance was classified as good (patch wearing and glasses use as prescribed before age 4 years, with either complete adherence or only brief periods of departure), fair (patch wearing and glasses use as prescribed before age 4 but with long periods of departure), or poor (refuses to wear patch and glasses, significantly less than prescribed) ${ }^{[6]}$. Unfortunately, the causes of fair or poor compliance were not mentioned in the examiner's notes.

\section{Surgical procedure}

The surgical intervention was performed rapidly after diagnosis of unilateral cataract. Underneath general anesthesia, the limbal approach was used for cataract extraction. Limbal incisions were done using MVR $20 \mathrm{G}$ just inside the end of limbal vessels with $1-\mathrm{mm}$ corneal tunnel, parallel to the iris plane then toward the anterior capsule. Viscoelastic material was used to fill and reform the anterior chamber. Anterior capsulorhexis was done using $23 \mathrm{G}$ capsulorhexis forceps with irrigation/aspiration of lens matter using vitrectomy probe or bimanual irrigation aspiration. Posterior capsulorhexis was done if the child aged from 1 to 3 years with anterior vitrectomy and without anterior vitrectomy if the age ranged from 4 to 6 years old. Patients older than 7 years were left with intact posterior capsule for PO YAG laser capsulotomy. Hydrophobic acrylic intraocular lens (IOL), either multipiece 


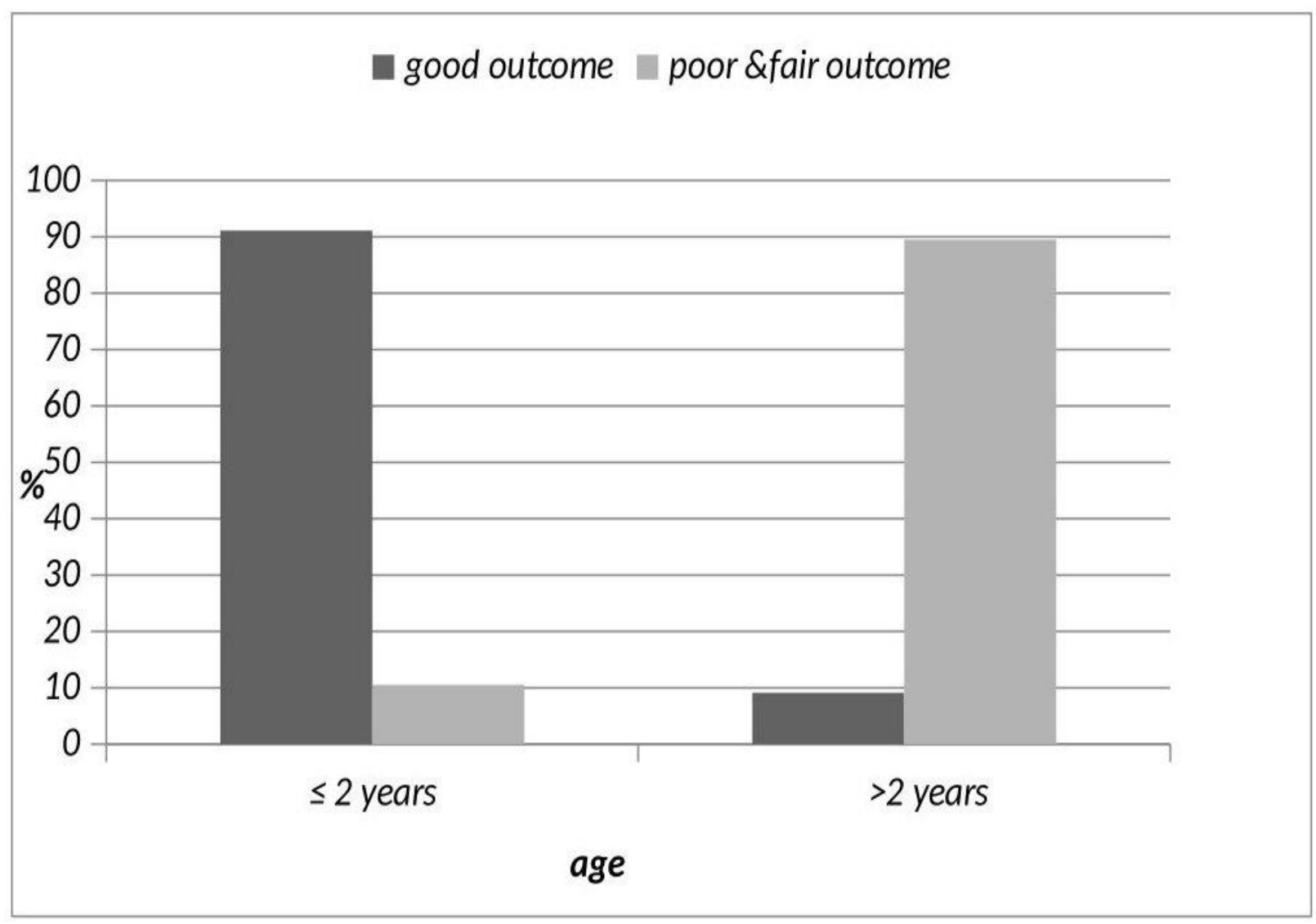

Relation between surgical age and visual outcome.

or single piece, was implanted in the ciliary sulcus or the capsular bag. The corneal wounds were closed using 10/0 nylon sutures and were removed 1 month PO. The PO medications were prescribed in the form of topical steroids, antibiotics, and cycloplegic eye drops.

Hand-held keratometer (Righton Retinomax K-plus3 autorefractometer/keratometer) was used underneath general anesthesia or automated keratometer for the cooperative children when awake to get theirK readings. The Sonomed machine (model-A scan) was used for axial length measurement, either under general anesthesia or with topical anesthesia. IOL power was calculated using SRK-II formula. Target PO refraction
Table 2 Values of preoperative IALD

\begin{tabular}{lccccc}
\hline & $N$ & $\begin{array}{c}\text { Minimum } \\
\text { IALD }(\mathrm{mm})\end{array}$ & $\begin{array}{c}\text { Maximum } \\
\text { IALD }(\mathrm{mm})\end{array}$ & $\begin{array}{c}\text { Mean } \\
\text { IALD } \\
(\mathrm{mm})\end{array}$ & SD \\
\hline Good & 11 & -1.00 & 2.00 & 0.2583 & 0.86353 \\
Fair & 5 & 1.50 & 2.00 & 1.7800 & 0.25884 \\
Poor & 14 & -2.00 & 5.50 & 2.2385 & 2.96747 \\
Total & 30 & -2.00 & 5.50 & 1.3700 & 2.19416 \\
\hline
\end{tabular}

IALD, interocular axial length difference.

was emmetropia if unilateral cataract presented after 1 year of age for future possible IOL exchange.

Glasses were prescribed and checked every 3 months with half waking hours patching. 


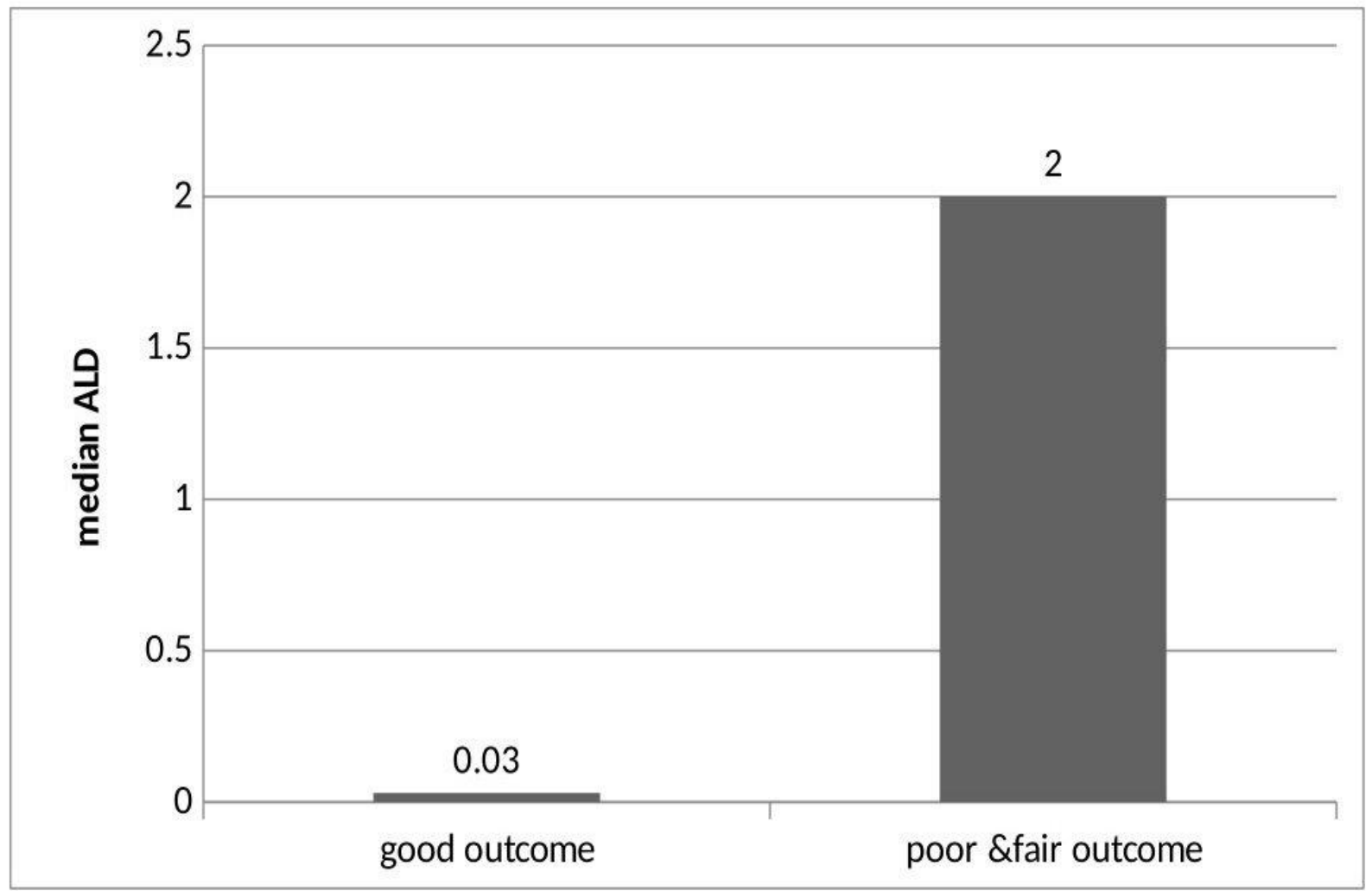

Primary outcome was best-corrected visual acuity at first month PO.

\section{Statistical analysis}

Covariates were the age at the time of surgery (months), the morphology of the cataract, preoperative strabismus (which could not be classified as a cause or a results of amblyopia), IALD, and compliance with amblyopia therapy. The choice of the covariates was supported by each clinical experience and former analysis. First, any statistical relationships between these potential predictors were investigated, and then $\chi^{2}$ was done.

\section{Results}

A total of 200 eyes were eligible for the study. Of them, 30 patients met our inclusion criteria and were used in the statistical analysis. The cataractous eye was longer than the healthy eye in 23 patients, whereas four eyes were shorter than the fellow eye and three eyes were comparable to the fellow eye.
The right eye was involved in 16 cases and the left eye in 14 cases. The mean age of presentation was 50 months (12-144 months) as shown in Table 1 with different clinical information. They were 18 females and 12 males.

Figure 1 illustrates that 11 patients had good vision and 91.9\% (10 cases) of them were younger than 2 years at the time of surgery, and only one case was older than 2 years. However, $100 \%$ of patients with fair vision and $85 \%$ of patients with poor vision were older than 2 years old (17 cases). A strong correlation $(P=0.001)$ was achieved in age below 2 years old.

The affected eye was longer than the healthy eye in 23 patients, whereas equal in three patients (all of them had good visual outcome) and shorter in four patients (one of them had a good visual outcome and different three patients had poor visual outcome), as shown in Table 2.

Mean IALD was $0.26 \mathrm{~mm}$ solely in patients with good visual outcome, whereas among children who had a fair and poor outcome, mean IALD was 1.78 and $2.24 \mathrm{~mm}$ 
respectively, as summarized in Fig. 2. Better visual prognosis seems to be related to small IALD $(P=0.008)$.

Figure 3 illustrates that all of the patients (11 eyes) who had good visual outcome were compliant with amblyopia therapy. Overall, 60\% (three eyes) of our patients with the fair visual outcome and $28.50 \%$ (four eyes) of these with poor visual outcome solely were compliant with amblyopia therapy $(P=0.001)$.

Overall, $54.5 \%$ of patients (six eyes) with good visual outcome had preoperative strabismus, whereas $80 \%$ (four eyes) and $57.5 \%$ (eight eyes) of patients with fair and poor visual outcome had preoperative strabismus, respectively. The good visual outcome was achieved in four eyes of lamellar cataract (36.4\%), a pair of eyes of nuclear (18.5\%), and a couple of eyes of posterior cataract $(18.5 \%)$ with fair and poor outcome within the remainder of patients. The associations of morphology of cataract and preoperative strabismus, whether exotropia/esotropia, were weakly correlated with $\mathrm{PO}$ visual acuity.

\section{Discussion}

The management of pediatric cataract and its $\mathrm{PO}$ complications throughout the last years has shown an excellent improvement and refinement. The assessment of child PO visual prognosis remains tough, though early surgical intervention plays a major role in its improvement. Regardless of the absolute IALD would be prognostic of a poor postoperative visual acuity' ${ }^{[6]}$ as we have a tendency to complete in our study.

Fangqin and coworkers in China ${ }^{[19]}$ are correlated with our study results. They explicitly concluded that just in case of dense cataract, lensectomy before three months of age, IOL implantation, correct managing of PO complications, early optical correction and aggressive PO patching of the sound eye would increase the ultimate visual outcome.

Gochnauer et al ${ }^{[6]}$ established that the median IALD in their study on 96 pediatric patients was $0.74 \mathrm{~mm}$. There was an $83 \%$ increase within the odds of poor $\mathrm{PO}$ visual acuity for each millimeter increase in IALD $(P=0.07)$. They hypothesized that a bigger absolute IALD would be prognostic of a poor PO visual acuity. This can be correlative with our study. The mean IALD in our study was 1.37 , and was $0.26 \mathrm{~mm}$ only in patients with good visual outcome $(P=0.008)$, whereas in children who had a fair outcome, the mean IALD was 1.87 and it had been of $2.24 \mathrm{~mm}$ in patients with poor outcome. best technical outcomes, visual outcome may be less reliable owing to difficulty of pediatric vision testing, as well as co-existing conditions such as amblyopia, latent nystagmus, strabismus, or PO refractive error, which must be managed at the same time ${ }^{[15]}$.

Pediatric cataract physicians are perpetually researching the factors that are present preoperatively in children with unilateral cataracts, which will affect their PO outcome. This would be useful in the choice of IOL power and parents' expectation of their child visual outcome, and therefore the importance of the strict application of amblyopia therapy.

In the general population, it is rare to search out IALD of larger than $0.5 \mathrm{~mm}$. However, it is common in patients with pediatric cataract ${ }^{[1]}$. The mean IALD in our study was 1.37 . The mean IALD was $0.26 \mathrm{~mm}$ solely in patients with good visual outcome, whereas children who had a fair and poor outcome, it was $1.87 \mathrm{~mm}$ and $2.24 \mathrm{~mm}$, respectively. It was reported in our study that patients with smaller IALD had better visual outcome.

The process of eye elongation as a result of visual deprivation has been demonstrated previously in animal models and human models $[6,10,16-18]$. In patients with IALD larger than $0.5 \mathrm{~mm}$, the visual system was already affected by deprivation amblyopia secondary to the cataract with the likelihood of a PO poor visual outcome. 'They hypothesized that a bigger before three months of age ends up in better PO visual outcomes.

\section{Conclusion}

In conclusion, there is a clinically vital relationship between a smaller IALD and PO good visual acuity especially when associated with younger age at time of surgery, earlier surgical intervention, and good compliance with amblyopia therapy.

\section{Acknowledgements}

Institution that the study was conducted: a tertiary referral hospital in Egypt 'ABO EI Reesh Children Hospital, Cairo University' and also Fayoum University Hospital.

The material was presented as a hard poster at the AAPOS annual meeting; March 2018 in Washington, DC.

The manuscript has been read and approved by all the authors. The requirements for authorship have been met. Each author believes that the manuscript represents honest work. 
Moreover, we concluded that higher visual prognosis proves to be related to good compliance with amblyopia therapy as all the patients in our study who had good visual outcome were compliant with amblyopia therapy, whereas $60 \%$ of patients with the fair visual outcome and $28.50 \%$ of these with poor visual outcome solely were compliant with amblyopia therapy. Unfortunately, we could not assess the explanation for that poor compliance because the study was retrospective; thus, we recommend special care and extra-time to resolve this critical issue. It goes with the opinion of Chak et al. ${ }^{[9]}$ who thought that compliance with amblyopia therapy (occlusion) was the foremost sturdy issue dominating the visual outcome in each bilateral or unilateral cataract.Ledoux et al. ${ }^{[8]}$ found that PO visual acuity was considerably completely different among patients younger than one year of age at the time of surgery and children older than 4 years of age. Their younger patients had the worst PO visual outcome due to associated ocular anomalies and the sensory deprivation effect throughout the vital visual period. This is opposite to our results. On comparing of our patients with good visual outcome with those with fair and poor outcomes, strongly correlative higher results were achieved in age below 2 years old (91.1\%) compared with those older than that.

It goes with the opinion of Birch et al. ${ }^{[20]}$, Birch and Stager ${ }^{[21]}$, Lundvall and Kugelberg ${ }^{[22]}$, and Ondraaek and Lokaj ${ }^{[23]}$ stating that early cataract extraction

11 Lambert SR, Buckley EG, Drews-Botsch C, Lynn M, Bridgman B, Celano M, et al. The infant aphakia treatment study: design and clinical measures at enrollment. Arch Ophthalmol 2010; 128:21-27.

12 Stewart CE, Fielder AR, Stephens DA, Moseley MJ. Unilateral amblyopia: factors influencing visual outcome. Invest Ophthalmol Vis Sci 2005; 46:3152-3160

13 Mistr SK, Trivedi RH, Wilson ME. Preoperative considerations and outcomes of primary intraocular lens implantation in children with posterior polar and posterior lentiglobus cataract. J AAPOS 2008; 12:58-61.

14 Donahue S. Relationship between anisometropia, patient age, and development of amblyopia. Trans Am Ophthalmol Soc 2005; 103:313-336.

15 Nihalani BR, VanderVeen DK. Benchmarks for outcome indicators in pediatric cataract surgery. Eye 2017; 31:417-421.

16 Wiesel T, Raviola E. Myopia and eye enlargement after neonatal lid fusion in monkeys. Nature 1977; 266:66-68.

17 Tigges M, Tigges J, Fernandes A, Eggers HM, Gammon JA. Postnatal axial eye elongation in normal and visually deprived rhesus monkeys. Invest Ophthalmol Vis Sci 1990; 31:1035-1046.

\section{Financial support and sponsorship \\ Nil.}

\section{Conflicts of interest}

There are no conflicts of interest.

\section{References}

1 Lal G, Trivedi R, Wilson M, Scarlett L, Peterseim M. Interocular axial length difference in eyes with pediatric cataracts. JAAPOS 2005; 9:358-362.

2 Kee CS, Hung LF, Qiao-Grider Y, Roorda A, Smith ELIII. Effects of optically imposed astigmatism on emmetropization in infant monkeys. Invest Ophthalmol Vis Sci 2004; 45:1647-1659.

3 Foster A, Gilbert C, Rahi J. Epidemiology of cataract in childhood: a global perspective. J Cataract Refract Surg 1997; 23:601-604.

4 Edmonds L, James L. Temporal trends in the prevalence of congenital malformations at birth based on the birth defects monitoring program, United States, 1979-1987. MMWR CDC Surveill Summ 1990; 39:19-23.

5 Kocur I, Resnikoff S. Visual impairment and blindness in Europe and their prevention. Br J Ophthalmol 2002; 86:716-722.

6 Gochnauer A, Trivedi R, Hill E, Wilson M. Interocular axial length difference as a predictor of postoperative visual acuity after unilateral pediatric cataract extraction with primary IOL implantation. J AAPOS 2010; 14:20-24.

7 Shirabe H, Suda K, Mori Y, Dogru M, Nakamura M, Sekiya Y, et al. Visual function following unilateral congenital cataract surgery. Am Orthopt $J$ 1998; 48:97-103.

8 Ledoux DM, Trivedi RH, Wilson MEJr, Payne JF. Pediatric cataract extraction with intraocular lens implantation: visual acuity outcome when measured at age four years and older. J AAPOS 2007; 11:218-224.

9 Chak M, Wade A, Rahi JS. Long-term visual acuity and its predictors after surgery for congenital cataract: findings of the British congenital cataract study. Invest Ophthalmol Vis Sci 2006; 47:4262-4269.

10 Troilo D. Neonatal eye growth and emmetropisation - a literature review. Eye 1992; 6:154-160.

18 Sorkin J, Lambert S. Longitudinal changes in axial length in pseudophakic children. J Cataract Refract Surg 1997; 23:624-628.

19 Fangqin MA, Ren M, Wang L, Wang Q, Guo J. Visual outcomes of dense pediatric cataract surgery in eastern China. PLoS One 2017; 12: e0180166.

20 Birch EE, Swanson WH, Stager DR, Woody M, Everett M. Outcome after very early treatment of dense congenital unilateral cataract. Invest Ophthalmol Vis Sci 1993; 34:3687-3699.

21 Birch EE, Stager DR. The critical period for surgical treatment of dense congenital unilateral cataract. Invest Ophthalmol Vis Sci 1996; 37:1532-1538.

22 Lundvall A, Kugelberg U. Outcome after treatment of congenital unilateral cataract. Acta Ophthalmol Scand 2002; 6:588-592.

23 Ondraaek O, Lokaj M. Visual outcome after congenital cataract surgery. Long-term clinical results. Scripta Medica (Brno) 2003; 76:95-102.

24 Rajan MS, Bunce C, Tuft S. Interocular axial length difference and agerelated cataract. J Cataract Refract Surg 2008; 34:76-79. 